\title{
Red foxes ( Vulpes vulpes) as reservoirs of respiratory capillariosis in Serbia
}

\author{
Tamara Ilić ${ }^{1}$, Zsolt Becskei $^{2}$, Aleksandar Tasić ${ }^{3}$, \\ Predrag Stepanović ${ }^{4}$, Katarina Radisavljević ${ }^{5}$, Boban Đurić ${ }^{6}$, Sanda Dimitrijević ${ }^{1}$ \\ ${ }^{1}$ Department for Parasitology, Faculty of Veterinary Medicine, University of Belgrade, 11000 Belgrade, Serbia \\ ${ }^{2}$ Department for Animal Breeding and Genetics, Faculty of Veterinary Medicine, \\ University of Belgrade, 11000 Belgrade, Serbia \\ ${ }^{3}$ Public Health Institute "Niš“, 18000 Niš, Serbia \\ ${ }^{4}$ Department for Equine, Small Animal, Poultry and Wild Animal Diseases, \\ ${ }^{5}$ Department of Animal Hygiene, \\ Faculty of Veterinary Medicine, University of Belgrade, 11000 Belgrade, Serbia \\ ${ }^{6}$ Veterinary Directorate, Regional Veterinary Inspection Office of Braničevo District, 12222 Braničevo, Serbia \\ beckeizolt@gmail.com
}

Received: October 28, $2015 \quad$ Accepted: May 16, 2016

\begin{abstract}
Introduction: The aim of the study was to determine the prevalence of respiratory capillariosis in red foxes (Vulpes vulpes) in some regions of Serbia. Material and Methods: The study was conducted on 102 foxes in six epizootiological regions of Serbia, during the hunting season between 2008 and 2012. Results: The presence of respiratory capillariosis in all tested epizootiological regions was confirmed. The E. aerophilus nematode was detected with overall prevalence of $49.02 \%$. The diagnosis of E. aerophilus infection was confirmed by the determination of morphological characteristics of adult parasites found at necropsy and the trichurid egg types collected from the bronchial lavage and the content of the intestine. Conclusion: The presented results contribute to better understanding of the epidemiology of this nematodosis in Serbia. However, the high prevalence of capillaries in tested foxes, demonstrated in all explored areas, might suggest that foxes from other regions in Serbia may also be infected. The fact that domestic carnivores and humans can also be infected enhances the importance of the overall epidemiological status. To establish the relevant prevalence of respiratory capillariosis, further investigations and continous monitoring of parasitic fauna of carnivores are needed in the whole country.
\end{abstract}

Keywords: foxes, Eucoleus aerophilus, epidemiology, Serbia.

\section{Introduction}

Respiratory capillariosis is a zoonotic disease, affecting both domestic and wild animals, as well as humans. The most common causative agent is the Eucoleus aerophilus (4) syn. Capillaria aerophila or Thominx aerophilus (11). This nematode is epidemically the most important species from the Capillaria genus. It can be found in the trachea and in the great bronchi, scarcely in the nasal cavity and frontal sinuses of cats (17), dogs (27), foxes $(1,25)$, coyotes (13), wolves (19), raccoons (23), bears, and other carnivores (6).

Male nematodes are about $32 \mathrm{~mm}$ long, while females are of 20-24 mm (26). The adult lungworms are parasites in the bronchioles, bronchi, and trachea of the definitive host. The females lay eggs that are coughed, swallowed, and released via faeces into the environment. The eggs reach the infective stage in about 30-45 d. Alternatively, development to the infective larval stage may occur in earthworms (i.e. facultative intermediate hosts). Animals become infected by ingesting the embryonated eggs or the earthworms. After ingestion, the larvae migrate to the lungs, where they evolve into adult and reach their sexual maturity after about 3-6 weeks post infection (p.i.) (26).

A respiratory infection of the dogs and cats with E. aerophilus occurs sporadically and has a subclinical course. However, in the last decade there have been 
many detected cases with clinical manifestation in animals (10), as well as infections in humans (15). Respiratory capilariosis has wide geographical distribution with cases described in North and South America, Europe, Asia, North Africa, and Australia (18). In Europe, it was most frequently diagnosed in wild canids $(2,9,16,21,25)$. There are data on affected cats and dogs in Italy $(10,27)$, and also in cats in Portugal (17). Investigations conducted in Serbia indicated high prevalence (84\%) of E. aerophilus in foxes in West Bačka region, Vojvodina (16). The epizootiological/epidemiological data on the dissemination and distribution of E. aerophilus in Europe are scarce and incomplete. It is assumed that climate change with global warming and geoclimatical changes are of great importance to the expansion of the disease (28). As the data on the occurrence of respiratory parasitic infections of wild carnivores in the region are insufficient $(7,8,12,20,29)$, the aim of this survey was to establish the presence, distribution, and prevalence of respiratory capillariosis in fox populations in six different epizootiological regions in Serbia.

\section{Material and Methods}

Study period and area. The study was conducted on 102 foxes, between 2008 and 2012. The foxes were culled during the hunting season in six epizootiological areas in Serbia: the West-Bačka, South-Banat, Kolubara, Braničevo, Raška, and Zaječar districts (Fig. 1).

Sampling. In order to determine the prevalence of infection with $E$. aerophilus, parasitic necropsy of the foxes was conducted, and adult and developmental stages of the parasites were assessed. All the tested foxes were adults with body weight ranging from 5.5 to $8.5 \mathrm{~kg}$. Twenty foxes were culled in West-Bačka, 8 in Southern-Banat, 16 in Kolubara, 12 in Braničevo, 19 in Raška, and 27 in Zaječar districts.

The trachea, bronchi, and lungs were examined macroscopically; $25 \mathrm{~g}$ of lung parenchyma was examined by Baermann's method, and a tracheal lavage was performed as well. The trachea was opened and examined throughout its length with the larynx until the bifurcation under binocular microscope at $50 \times$ magnification. The material was examined fresh or preserved in 30\% ethyl alcohol. A detailed morphometric and morphological analysis of trichurid egg types (3) and adult forms of the parasites found (22) was performed, and the obtained characteristics confirmed the presence of E. aerophilus.

In order to determine other helminthes (trematodes, cestodes, and other nematodes), morphological identification of the parasites was performed after necropsy. The mucosa of the small intestine was scraped and the intestinal contents were washed with tap water into $500 \mu \mathrm{m}$ and $212 \mu \mathrm{m}$ sieves by means of a water jet. Based on the shape, size, and number of rostellar hooks of the parasites (30), they were initially diagnosed at the genus level as taenia worms.

The content of the intestine was examined by qualitative methods for the presence of helminth eggs and coccidia oocysts. The method applied was flotation in saturated aqueous $\mathrm{NaCl}$ solution (specific gravity of 1.200 at $20^{\circ} \mathrm{C}$ ) and saturated aqueous $\mathrm{ZnSO} 4$ solution (specific gravity 1.300 to 1.400 at $20^{\circ} \mathrm{C}$ ).

The intensity of the infection was classified on the basis of the number of adult forms of E. aerophilus in the lungs: no worms, slight (1-5 adults), mild (5-20), and moderate (more than 20) infection.

\section{Results}

The adult form of E. aerophilus lungworm was diagnosed in 50 out of 102 tested foxes from the territory of northern and central Serbia. In six districts analysed, the following prevalence of respiratory capillariosis was noted: in West-Bačka -6 out of 20 , in Southern-Banat -3 out of 8 , in Kolubara -7 out of 16 , in Braničevo -4 out of 12 , in Raška - 10 out of 19 , and in Zaječar -20 out of 27 (Fig. 1).

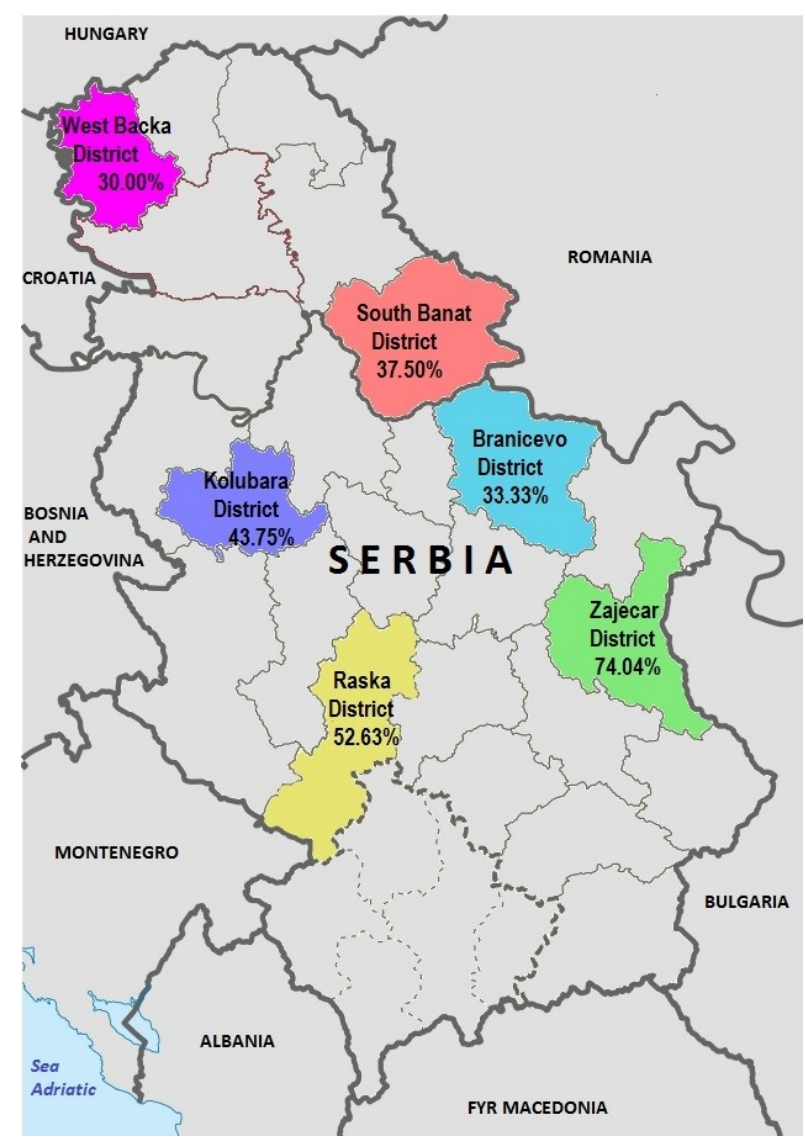

Fig. 1. Survey of distribution and prevalence of E. aerophilus in some districts of Serbia

Differences were detected $(\mathrm{P}<0.05)$ in the prevalence of capillariosis among different districts, 
with the highest prevalence in Zajecar District (74.04\%) (Table 1).

The intensity of infection varied from slight to moderate (range 1-34), with an average of nine adult worms detected. In 24 out of 102 foxes a moderate intensity of infection was established, slight intensity was detected in 20 out of 102, while moderate in 6 out of 102 (Fig. 2).

Using light microscopy, E. aerophilus barrel-like eggs (length 60-65 $\mu \mathrm{m}$, width 25-40 $\mu \mathrm{m}$ ) with asymmetry of bipolar plugs and walls with a network of anastomosing ridges were detected (Fig. 3A). The parasite eggs were found in bronchial lavage and intestinal content. Differential diagnosis between similar eggs of E. aerophilus and Trichuris vulpis
(Fig. 3B) was performed on the basis of the differences in size and symmetry of the polarities (T. vulpis eggs are 70-80 $\mu \mathrm{m}$ long, $30-50 \mu \mathrm{m}$ wide and have symmetrically placed poles).

Seven species of endoparasites were detected in the intestinal contents of the infected foxes (Table 2), with the highest prevalence of $A$. alata species (47.05\%) and T. canis (41.17\%). In mixed infections, the most common was polyparasitism A. alata T. vulpis and T. canis - A. caninum (18.62\%). A slightly higher prevalence of trichiuriosis (28.43\%) was diagnosed in relation to the prevalence of respiratory capilariosis $(22.55 \%)$. No intestinal parasites were detected in $14.70 \%$ of the examined foxes.

Table 1. The prevalence of respiratory capillariosis in foxes in six districts of Serbia between $2008-2012$

\begin{tabular}{|c|c|c|c|c|c|c|}
\hline District & $\begin{array}{l}\text { Number of } \\
\text { examined } \\
\text { foxes }\end{array}$ & $\begin{array}{l}\text { Number of } \\
\text { positive foxes }\end{array}$ & $\begin{array}{l}\text { Prevalence } \\
(\%)\end{array}$ & $95 \% \mathrm{CI}$ & $\chi^{2}$ & $\mathrm{P}$ \\
\hline West Backa & 20 & 6 & $30.0 \%$ & $9.92-50$ & \multirow{6}{*}{11.56} & \multirow{6}{*}{$0.04^{*}$} \\
\hline South Banat & 8 & 3 & $37.5 \%$ & $4-71$ & & \\
\hline Kolubara & 16 & 7 & $43.75 \%$ & $19.7-68$ & & \\
\hline Branicevo & 12 & 4 & $33.33 \%$ & $6.7-59.90$ & & \\
\hline Raska & 19 & 10 & $52.63 \%$ & $30.1-75.05$ & & \\
\hline Zajecar & 27 & 20 & $74.04 \%$ & $57.54-90.58$ & & \\
\hline
\end{tabular}

$* \mathrm{P}<0.05$

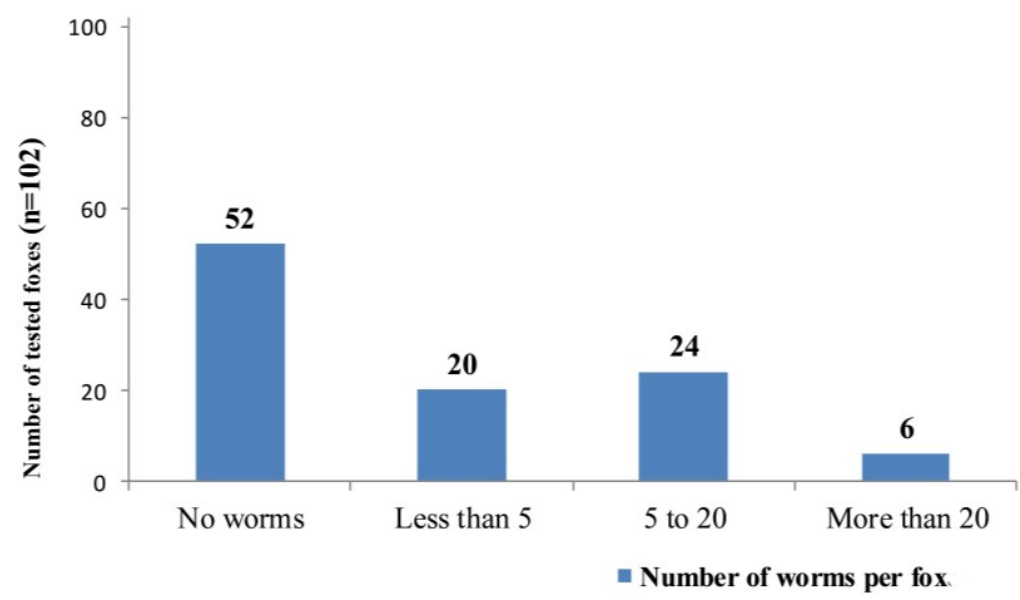

Fig. 2. Number of E. aerophilus adult nematodes per foxes

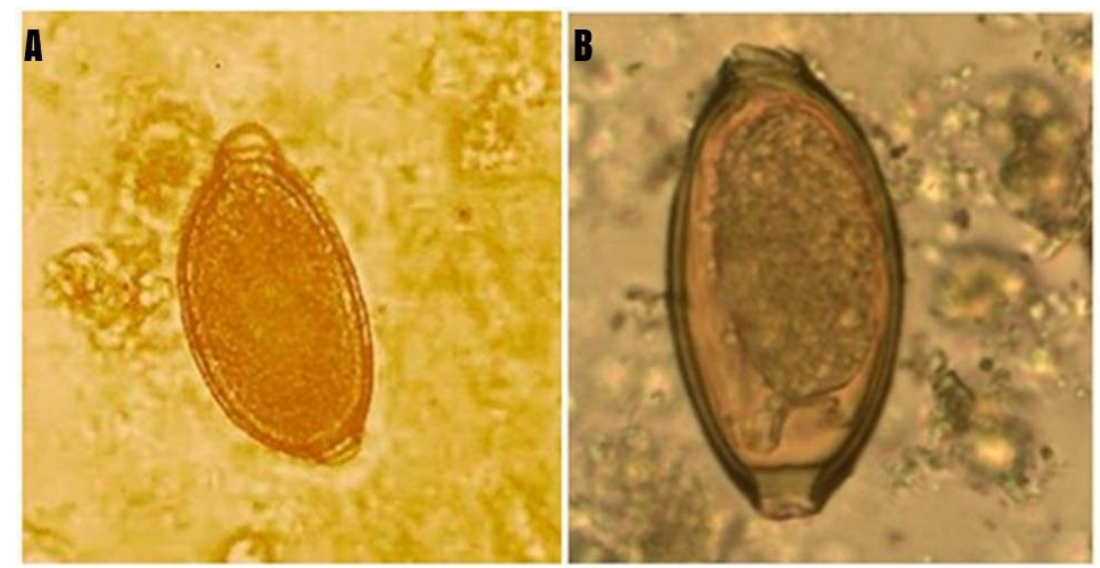

Fig. 3. Eggs of Eucoleus aerophilus (A) and Trichuris vulpis (B) detected in the content of the intestine (400× magnification) 
Table 2. Endoparasites detected in the content of the intestine of the tested foxes $(\mathrm{N}$ - number of foxes scored positive for endoparasites; \% - infection rate)

\begin{tabular}{|c|c|c|c|c|c|}
\hline \multirow{2}{*}{ Endoparasite species } & \multicolumn{2}{|c|}{ Number of foxes } & \multirow[t]{2}{*}{ Mixed infections } & \multicolumn{2}{|c|}{ Number of foxes } \\
\hline & $\mathrm{N}$ & $\%$ & & $\mathrm{~N}$ & $\%$ \\
\hline Isospora spp. & 3 & 2.94 & $\begin{array}{l}\text { A. alata } \\
\text { T. vulpis }\end{array}$ & 19 & 18.62 \\
\hline Alaria alata & 48 & 47.05 & $\begin{array}{l}\text { A. alata } \\
\text { E. aerophilus }\end{array}$ & 14 & 13.72 \\
\hline Taenia spp. & 2 & 1.96 & $\begin{array}{l}\text { T. canis } \\
\text { A. caninum }\end{array}$ & 19 & 18.62 \\
\hline Toxocara canis & 42 & 41.17 & $\begin{array}{l}\text { A. alata } \\
\text { T. canis } \\
\text { T. vulpis }\end{array}$ & 7 & 6.86 \\
\hline Ancylostoma caninum & 35 & 34.31 & $\begin{array}{l}\text { A. alata } \\
\text { E. aerophilus } \\
\text { T. canis } \\
\end{array}$ & 9 & 8.82 \\
\hline Trichuris vulpis & 29 & 28.43 & $\begin{array}{l}\text { T. canis } \\
\text { T. vulpis } \\
\text { A. caninum }\end{array}$ & 3 & 2.94 \\
\hline Eucoleus aerophilus & 23 & 22.55 & $\begin{array}{l}\text { T. canis } \\
\text { A. caninum } \\
\text { Isospora spp. }\end{array}$ & 2 & 1.96 \\
\hline
\end{tabular}

\section{Discussion}

Eucoleus aerophilus mainly affects the respiratory system of foxes, but it can also be found in dogs, cats, and other carnivores in some regions of Europe, as well as North and South America. The infection with this nematode is very frequent in wild carnivores, so the fact that infections of humans are not common may be surprising. Wild carnivores, usually highly infected foxes and jackals, are infection reservoirs for dogs and cats in urban areas (predominantly suburbs). As the disease has a zoonotic character, the risk of human infection, through cats and dogs is heightened $(25,28)$.

In different European countries, different prevalence of the infection was found in red foxes, e.g.: $5 \%$ in Zagreb county in Croatia (21), 66\% in Hungary (25), $88 \%$ in Norway (9), and $0.3 \%$ in central Poland (2).

After the first human case of $E$. aerophilus infection in Serbia, there is an increased interest in the prevalence and distribution of the nematode in wild and domestic carnivores. The results of the present survey proved the presence of the E. aerophilus infection in all six examined districts of Serbia, with the overall prevalence of $49.02 \%$. The highest prevalence was detected in Zaječar and Raška districts, where it reached 74.04\% (95\% CI: 57.54-90.58) and 52.63\% (95\% CI: 30.175.05), respectively. Zapadno-Bački and Braničevski districts showed a prevalence at 30.0\% (95\% CI: 9.92$50)$ and $33.33 \%$ (95\% CI: 6.7-59.90), respectively. The prevalence of the infection in Južno-Banatski and Kolubarski districts reached 37.50\% (95\% CI: 4-71) and $43.75 \%$ (95\% CI: 19.7-68) respectively. According to Lalošević et al. (16) who screened respiratory capillariosis of red foxes in the northern part of Serbia, the prevalence of this nematodosis was at the level of $84 \%$. Our results showed a significantly lower prevalence in the majority of the tested districts, except Zaječar region. In other European countries, the prevalence of respiratory capillariosis of red foxes varied in wide range from $0.3 \%$ to $88 \%$. The most similar prevalence, compared to our results, was detected in Hungary $66 \%$ (25). In the suburbs of cities and villages, wild carnivores often share the habitat with cats and dogs. These observations are very valuable epizootiological data. It can be assumed that during more intensive urbanisation of cities, the contact between populations of cats, stray dogs, and foxes is going to be more frequent, proving that the epizootiology of respiratory capillariosis is becoming significantly important. It is obvious that the population of foxes is a constant reservoir of infection of domestic carnivores in the suburban areas. The survey conducted by Ilić et al. (14) on cats between 2003 and 2007 on the territory of Belgrade, including its suburbs, demonstrated that $8.03 \%$ of the cats were infected with E. aerophilus. The results of this research contribute to a better understanding of the epidemiology of respiratory capillariosis in Serbia.

To predict the spread of some zoonoses in certain regions of Serbia, for which foxes are the source of infection, it is crucial to monitor the parasitic fauna of these wild animals. Pulmonary capillariosis in humans has also been documented in France, Russia, Ukraine, and Iran (5). Due to the fact that a very limited number of human infections have been documented so far, the incubation period is unknown; however, some authors believe that it could be similar to the prepatent period in animals $(5,15)$. Since respiratory capillariosis is a potential threat to humans, preventive measures are of high importance (24).

This study contributes to a better understanding of the epizootiological situation of respiratory capillariosis of foxes in six investigated regions in Serbia. As wild carnivores are considerable reservoirs for infection of dogs and cats, the obtained data could promote some new strategies for the monitoring of parasitic infections of the hunted foxes. Such monitoring could be carried out in the future as a part of the routine diagnostic procedure. 
Conflict of Interests Statement: The authors declare that there is no conflict of interests regarding the publication of this article.

Financial Disclosure Statement: The research and the article were financed with the Authors' own funds, with the support of the Ministry of Science and Technological Development of Republic of Serbia.

Animal Rights Statement: The survey was conducted on culled foxes.

\section{References}

1. Al-Sabi S.N.M., Halasl T., Kapel O.M.: Infections with cardiopulmonary and intestinal helminths and sarcoptic mange in red foxes from two different localities in Denmark. Acta Parasitol 2014, 59, 98-107.

2. Borecka A., Gawor J., Malczewska M. Malczewski A.: Prevalence of zoonotic helminth parasites of the small intestine in red foxes from central Poland. Med Weter 2009, 65, 33-35.

3. Conboy G.A.: Helminth parasites of the canine and feline respiratory tract. Vet Clin North Am Small Anim Pract 2009, 39, 1109-1126.

4. Creplin F.C.H.: Eingeweidewtirmer, Finnenwiirmer, Thierwtirmer, Allg. In: Encycl. d. Wissensch u. Kunste. Ersch \& Gruber. Leipzig, 1839, 1 Sect. pp. 277-302.

5. Cross J.H.: Capillariosis. In: Zoonoses. Biology, Clinical Practice, and Public Health Control. Edited by Palmer S.R., Lord Soulsby, Simpson D.I.H., Oxford University Press, 1998, pp. 789-802.

6. Crum J.M., Nettles V.F., Davidson W.R.: Studies on endoparasites of the black bear (Virsus americanus) in the south eastern United States. J Wild Dis 1978, 14, 178-186.

7. Ćirović D., Pavlović I., Penezić, A.: Intestinal helminth parasites of the grey wolf (Canis lupus L.) in Serbia. Acta Vet Hung 2015, 63, 189-198.

8. Ćirović D., Penezić A., Pavlović I., Kulišić Z., Ćosić N., Burazerović J. Maletić V.: First records of Dilofilaria repens in wild canids from the region of Central Balkan. Acta Vet Hung 2014, 62, 481-488.

9. Davidson R.C., Gjerde B., Vihoren T., Lillehaug A., Handerland H.: Prevalence of Trichinella larvae and extraintestinal nematodes in Norwegian red foxes (Vulpes vulpes). Vet Parasitol 2006, 136, 307-316.

10. Di Cesare A., Castagna G., Otranto D., Meloni S., Milillo P., Latrofa S.M., Paoletti B., Bartolini R., Traversa D.: Molecular diagnosis of Capillaria aerophila, an agent of canine and feline pulmonary capillariosis. J Clin Microbiol 2012, 50,1958-1963.

11. Dujardin F.: Histoire naturelle des helminthes ou vers intestinaux. In: Encyclopedie de Roret. Paris, France, 1845, p. 654.

12. Gavrilović P., Blitva-Robertson G., Özvegy J., Kiskároly F., Becskei Z.: Case report of dirofilariasis in grey wolf in Serbia. Acta Parasitol 2015, 60, 175-178.

13. Gompper M.E., Goodman R.M., Kays R.W., Ray J.C., Fiorello C.V., Wade S.E.: A survey of parasites of coyotes (Canis latrans) in New York based on fecal analysis. J Wild Dis 2003, 39 , 712-717.

14. Ilić T., Dimitrijević S., Mitrović S., Džamić A., Djurić B.: Capillariosis - opportunistic zoonosis. In: Proc book of the XIV Annual X Conference of Veterinarians of the Republic of Srpska Jahorina. Bosnia and Herzegovina. 2009, p. 78.

15. Lalošević D., Lalošević V., Klem I., Stanojev-Jovanović D., Pozio E.: Pulmonary capillariasis miming bronchial carcinoma. Am J Trop Med Hyg 2008, 78, 14-16.

16. Lalošević V., Lalošević D., Čapo I., Simin V., Galfi A., Traversa D.: High infection rate of zoonotic Eucoleus aerophilus infection in foxes from Serbia. Parasite 2013, 20, 1-5.

17. Madeira de Carvalho L.M., Pereira da Fonseca L.M., Gomes L., Meireles J.M.: Lungworms in domestic and wild carnivores in Portugal: rare parasites or rarely diagnosed? Proceedings of $19^{\text {th }}$ Annual Congress of the European College of Veterinary Internal Medicine, Porto, Portugal, 2009, p. 28.

18. Mc Carthy J., Moore T.A.: Emerging helminth zoonoses. Int J Parasitol 2000, 30, 1351-1360.

19. Pence D.B., Bryant F.C.: Effect of short term coyote removal on populations of coyote helminths. J Wild Dis 2002, 38, 54-67.

20. Penezić A., Selaković A., Pavlović I., Ćirković D.: First findings and prevalence of adult heartworms (Dirofilaria immitis) in wild carnivores from Serbia. Parasitol Res 2014, 113, 3281-3285.

21. Rajković R., Marinculić A., Bosnić S., Benić M., Vinković B., Mihaljević Ž.: Prevalence and seasonal distribution of helminth parasites in red foxes (Vulpes vulpes) from the Zagreb County (Croatia). Z Jagdwiss 2002, 48, 151-160.

22. Romashov B.V.: Three capillariid species (Nematoda, Capillariidae) of carnivores (Carnivora) and discussion of system and evolution of the nematode family Capillariidae. 1. Redescription of Eucoleus aerophilus and E. boehmi. Zool Zh 2000, 79, 1379-1391

23. Schuster R., Nöckler K., Mix H.: Helminth findings in indigenous racoon dogs Nyctereutes procyonoides (Gray, 1834). Berl Munch Tierarztl Wochenschr 2001, 114, 273-276.

24. Stanojev-Jovanović D., Kuruc V., Pavlović S., Perin B., Klem I., Lalošević D.: Eucoleus (Capillaria) aerophila i eozinofilna pneumonija, Zbornik Radova Majski Pulmološki Dani, 2006, 229-233.

25. Szell Z., Marucci G., Pozio E., Vorgi I.: Extraintestinal nematode infections of red foxes (Vulpes vulpes) in Hungary, Vet Parasitol 2003, 115, 329-334.

26. Traversa D., Di Cesare A., Li R.P., Castagn G., Meloni S., Heine J., Strube K., Milillo P., Otranto D., Meckes O., Schaper R.: New insights into morphological and biological features of Capillaria aerophila (Trichocephalida, Trichuridae). Parasitol Res 2011, 109, 97-104.

27. Traversa D., Di Cesare A., Milillo P., Iorio R., Otranto D.: Infection by Eucoleus aerophilus in dogs and cats: is another extraintestinal parasitic nematode of pets emerging in Italy Res Vet Sci 2009, 87, 270-272.

28. Traversa D., Di Cezare A., Conboy G.: Canine and feline cardiopulmonary parasitic nematodes in Europe: emerging and understimated. Parasit Vectors 2010, 3, 62.

29. Vengušt G.: Intestinal parasites of the red fox (Vulpes vulpes) in Slovenia. Acta Vet Hung 2013, 61, 454-462.

30. Verster A.: A taxonomic revision of the genus Taenia linnaeus, 1758s. Onderstepoort J Vet Res 1969, 36, 3-58. 